\title{
Portal Vein Stenosis Caused by Postoperative Complications after Pancreatobiliary Surgery
}

\author{
Hiroyuki Kinoshita*, Hideaki Tsubakihara, Shinji Yamazoe, Tomoya Kato, Kazunari Mori \\ Department of Surgery, Naga Municipal Hospital, Wakayama, Japan \\ Email: *hkino@nagahp.jp
}

How to cite this paper: Kinoshita, H., Tsubakihara, H., Yamazoe, S., Kato, T. and Mori, K. (2017) Portal Vein Stenosis Caused by Postoperative Complications after Pancreatobiliary Surgery. Surgical Science, 8, 326-333.

https://doi.org/10.4236/ss.2017.88036

Received: July 24, 2017

Accepted: August 13, 2017

Published: August 16, 2017

Copyright $\odot 2017$ by authors and Scientific Research Publishing Inc. This work is licensed under the Creative Commons Attribution International License (CC BY 4.0).

http://creativecommons.org/licenses/by/4.0/

(c) (i) Open Access

\begin{abstract}
Background: Portal vein (PV) stenosis or obstruction is sometimes observed in patients who were performed pancreatobiliary surgery. These conditions such as pancreatic fistulas (PF) and intra-abdominal infections after pancreatobiliary surgery still represent significant clinical issues. In addition, insufficient attention is paid to the fact that severe stenosis of the PV can result in life-threatening complications. Material and Methods: At our institution, lymph node dissection within the hepatoduodenal ligament was performed for biliary or pancreatic neoplasms in 68 patients between October 2005 and April 2017. The diameter of the PV was measured on computed tomography scans obtained before and after the operation. PV stenosis was defined as a $>50 \%$ reduction in the diameter of the PV. The degree of PF (Pancreatic Fistula) was defined by the International Study Group of Pancreatic Fistula after pancreaticoduodenectomy. Furthermore, the Clavien-Dindo (CD) classification was used to assess the complications that occurred in cases in which pancreatojejunostomy was not performed. The relationship between the degree of PV stenosis and the occurrence of postoperative complications was analyzed. Results: The overall frequency of PF was 56.3\% (18 patients). Grade $\mathrm{B}$ or C PF occurred in 5 patients (15.6\%). In the present small series, a correlation was detected between the degree of PV stenosis and the occurrence of postoperative complications after pancreatobiliary surgery $(\mathrm{p}<0.05)$. Conclusions: Clinicians should keep in mind that the PV can narrow in cases in which grade B or C PF or intra-abdominal abscesses occur after pancreatobiliary surgery.
\end{abstract}

\section{Keywords}

Portal Vein Stenosis, Pancreatobiliary Surgery, Pancreatic Fistula, Intra-Abdominal Infection 


\section{Introduction}

Portal vein (PV) stenosis or obstruction can be caused by tumor invasion [1], radiotherapy [2] [3], and surgical procedures such as liver transplantation or PV resection during pancreatic resection [4] [5]. After lymph node dissection within the hepatoduodenal ligament for a pancreatobiliary neoplasm, the PV is directly exposed in the region around the pancreatic or biliary anastomosis; therefore, it is considered that it is affected by the conditions in this area. Long-standing PV stenosis or obstruction can lead to portal hypertension; splenomegaly; and recurrent gastrointestinal bleeding, which is still considered to be a fatal complication. The purpose of the present study is to examine the relationship between the extent of PV stenosis and the occurrence of postoperative complications, such as pancreatic fistulas (PF) or intra-abdominal infections, after pancreatobiliary surgery.

\section{Material and Methods}

From October 2005 to April 2017, 68 patients underwent dissection of the lymph nodes within the hepatoduodenal ligament for biliary or pancreatic neoplasms at our institution. Skeletonization of the PV and hepatic artery was performed by removing all of the tissue in the hepatoduodenal ligament. PV is directly exposed in the region around the pancreatic or biliary anastomosis; therefore, it is considered that it is affected by the conditions in this area. We excluded patients with ampullary carcinoma, those who underwent PV reconstruction for tumor invasion, and those in which a locally recurrent lesion developed in close proximity to the PV. We collected the patients' clinicopathological data and radiological images from their electronic medical records and retrospectively analyzed the patency of the PV. Consequently, the remaining 43 patients were enrolled in this study. The diameter of the PV was measured on portal venous phase computed tomography (CT) images with a thickness of $5 \mathrm{~mm}$ at 3 months after surgery. In particular, the narrowest point of the PV at 8 weeks after the pancreaticobiliary surgery was defined as the postoperative PV diameter in order to ensure that our results were not affected by transient portal stenosis [6]. The observed postoperative changes in PV diameter are presented as percentage values compared with the preoperative diameter of the PV. PV stenosis was defined as $>50 \%$ narrowing of the diameter of the PV, as described in previous reports [7] [8]. The frequency of PF (as defined by the International Study Group of Pancreatic Fistula, ISGPF) [9] after pancreaticoduodenectomy was analyzed. PF was classified into four categories (none and grades A, B, and C). In addition, the Clavien-Dindo (CD) classification [10] was used to assess the complications that arose in cases in which pancreatojejunostomy was not performed. Then, the relationships between the grade of PF or the occurrence of a complication included in the CD classification and the extent of PV stenosis were studied. Data analyses were performed using the R statistical package version 3.1.0 (The R Foundation for Statistical Computing). Statistical associations between categorical factors were 
assessed using Fisher's exact test. P-values of $<0.05$ were considered to be statistically significant.

\section{Results}

Among the 43 patients, there were 30 males and 13 females with a mean age of 69 years (range: 52 - 86 years). The patients' underlying diseases included distal cholangiocarcinoma in 16 patients, pancreatic adenocarcinoma in 17 patients, gall bladder cancer in 9 patients, and hilar cholangiocarcinoma in one patient. Pylorus preserving or resecting pancreaticoduodenectomy (PpPD or PrPD) was performed in 32 patients; wedge resection of the gall bladder bed and the extrahepatic bile duct was carried out in 7 patients; and cholecystectomy combined with lymph node dissection within the hepatoduodenal ligament was done in 2 patients; and total pancreatectomy and left lobectomy of the liver together with extrahepatic bile duct resection, and lymph node dissection within the hepatoduodenal ligament were performed in one case each. Patient characteristics are shown in Table 1. The frequency of PF after pancreaticoduodenectomy was $56.3 \%$ (18 patients). Grade A PF occurred in 13 patients (40.6\%), and grade B or $\mathrm{C} P \mathrm{PF}$, which have a clinically significant impact on patient outcomes after surgery, occurred in 5 patients (15.6\%). According to the CD classification of surgical complications, among the cases in which pancreatojejunostomy was not performed 2 patient experienced a grade III complication (an intra-abdominal infection). Then, we examined relationship between the extent of PV stenosis and the occurrence of postoperative complications after pancreatobiliary sur-

Table 1. Patient characteristics.

\begin{tabular}{ll}
\hline $\begin{array}{c}\text { Number of patients } \\
\text { Age (years) }\end{array}$ & 43 \\
Gender (male/female) & $69(52-86)$ \\
Diagnosis & $30 / 13$ \\
Hilar cholagiocarcinoma & 1 \\
Distal cholangiocarcinoma & 16 \\
Pancreatic cancer & 17 \\
Gallbladder cancer & 9 \\
Surical procedure & \\
PpPD and PrPD & 32 \\
TP & 1 \\
Resction of GBB and EHBD \\
Cholecystectomy and LND
\end{tabular}




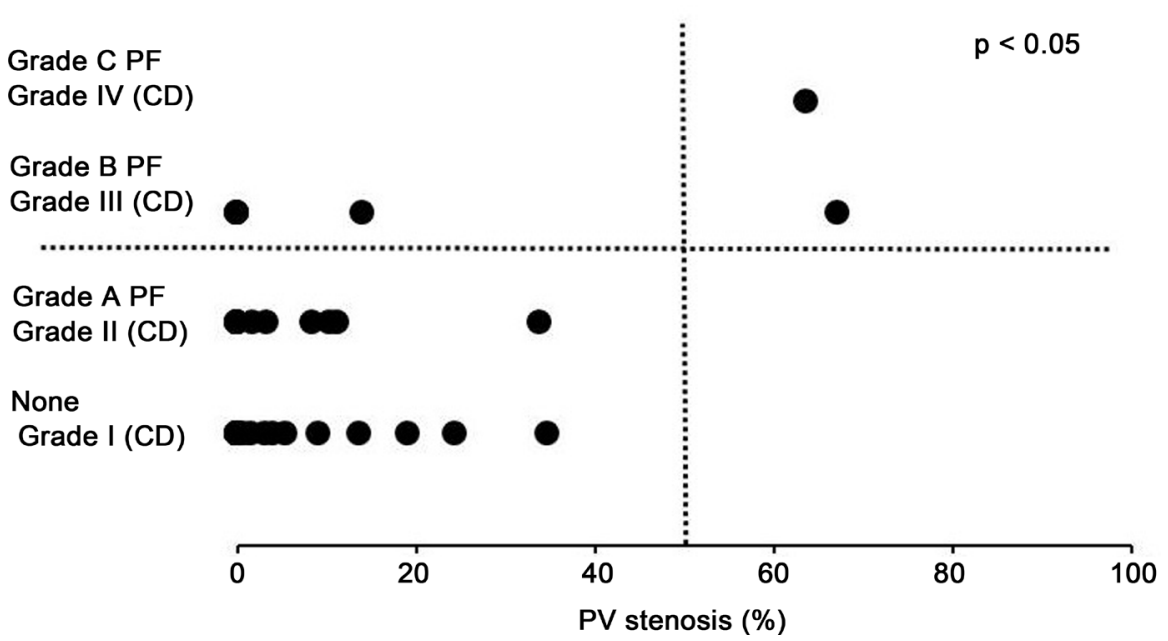

Figure 1. A relationship was detected between the extent of the reduction in the diameter of $\mathrm{PV}$ and the occurrence of postoperative complications after pancreatobiliary surgery ( $\mathrm{p}$ $<0.05)$.

gery. As shown in Figure 1, a correlation was detected between these factors ( $\mathrm{p}<$ $0.05)$.

\section{Representative Cases}

Case 1

A 66-year-old man visited our hospital complaining of jaundice. He had undergone PpPD for distal bile duct cancer. A CT scan obtained 12 days after the procedure revealed the presence of ascites and free air in the abdominal cavity. An emergency laparotomy was carried out under a diagnosis of grade C PF. Anastomotic leakage was observed at the pancreatojejunostomy after the PpPD. Therefore, a few stitches and an omentoplasty were performed in the anastomotic portion of the pancreatojejunostomy. The patient was discharged on postoperative day 152. However, he developed melena 3 years and 4 months later. CT revealed jejunal varices at the hepatic hilum and PV stenosis of $63 \%$ in comparison with the previous image (Figure 2). The melena recurred 1 - 4 times a year. Although we recommended that a metallic stent should be inserted after PV angioplasty for PV stenosis, we were not able to obtain the patient's consent.

Case 2

A 59-year-old female was referred to our hospital because of epigastralgia. Blood analysis detected severe inflammatory changes, and CT showed severe thickening of the gall bladder wall and an abscess. At first, cholecystectomy and drainage were performed under a preoperative diagnosis of xanthogranulomatous cholecystitis. However, a histopathological examination of the surgical specimens detected incidental gall blabber cancer, which had invaded the perimuscular connective tissue. On the $13^{\text {th }}$ postoperative day, wedge resection of the gall bladder bed and the extrahepatic bile duct together with lymph node dissection within the hepatoduodenal ligament were performed for advanced gall bladder cancer. The patient developed an intra-abdominal abscess during the postopera- 


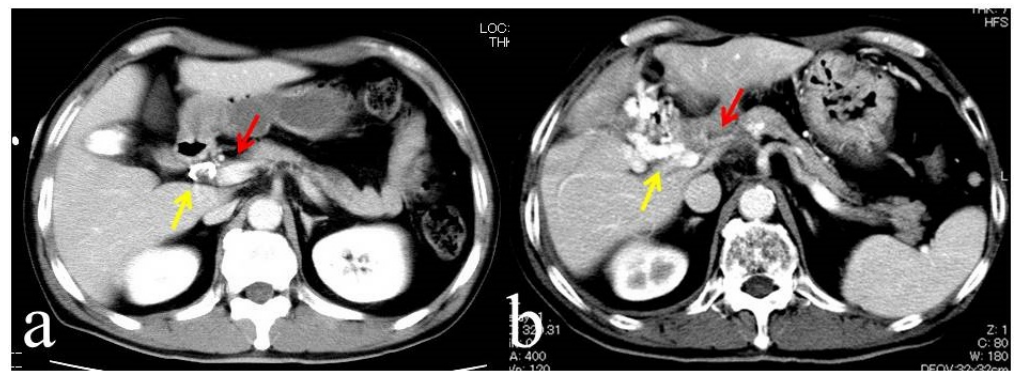

Figure 2. (a) A percutaneous transhepatic biliary drainage tube (yellow arrow) was inserted into the common bile duct. The preoperative diameter of the PV was normal (red arrow); (b) CT revealed jejunal varices in the hepatic hilum (yellow arrow) and PV stenosis (red arrow).

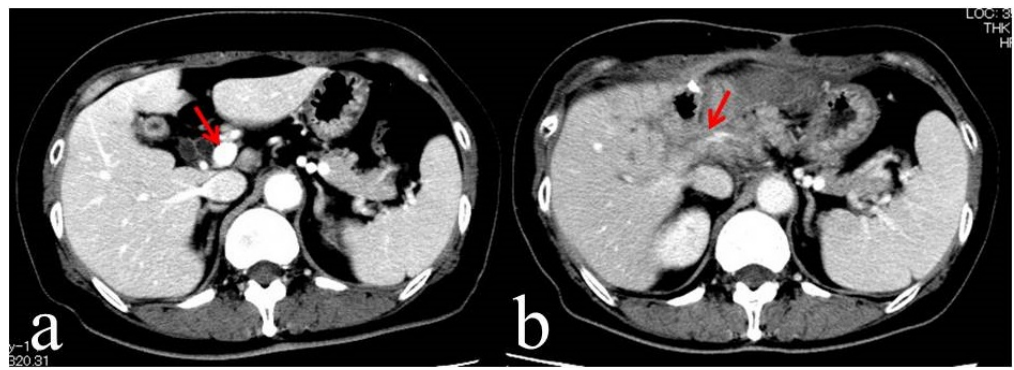

Figure 3. (a) The preoperative diameter of the PV was normal (red arrow); (b) PV stenosis was detected on the postoperative CT scan (red arrow).

tive period, and abscess drainage was carried out. The patient was discharged on postoperative day 63. Four months later, CT revealed PV stenosis of $67 \%$ in comparison with the previous image (Figure 3). Fortunately, no gastrointestinal bleeding was observed, but she died due to peritoneal dissemination at 2 years after the surgery.

\section{Discussion}

The hepatoduodenal ligament contains blood vessels, lymph nodes, and connective tissue. When lymph node dissection is performed in this region, all of the tissue except the hepatic artery and PV are removed. Therefore, these blood vessels are exposed after lymph node dissection and so are easily affected by the surrounding environment. On the other hand, postoperative complications occur at relatively constant frequencies after pancreatobiliary surgery. Of these, postoperative PF and intra-abdominal infections are considered to be important complications, but the rupturing of a pseudoaneurysm is the most serious and life-threating condition [11]. It is assumed that these complications have adverse effects on the PV. However, PV stenosis caused by postoperative complications can take several months to years to develop. Thus, the effects of PV stenosis have received little attention. In this study, we examined whether the postoperative complications that arise after lymph node resection within the hepatoduodenal ligament affect the PV.

At our institution, the frequency of PF after pancreaticoduodenectomy was 
$56.3 \%$, although a large-scale aggregated study suggested that the post-pancreaticoduodenectomy incidence of this condition is 30.2\% [12]. Grade B or C PF occurred in $15.6 \%$ cases, which was equal to the frequency observed in the latter study [12]. The current study revealed that PV was more susceptible to narrowing in cases involving grade $\mathrm{B}$ or $\mathrm{C} \mathrm{PF}$ or intra-abdominal infection than in cases that did not involve complications or in which grade A PF occurred after pancreatobiliary surgery. The features of the PV; i.e., its normal thickness and pressure values range from $0.5-1.0 \mathrm{~mm}$ and from $5-10 \mathrm{mmHg}$, respectively, might partly explain our findings [13] [14]. Specifically, it is suggested that the PV is more susceptible to the effects of periportal inflammation and PF-associated fibrosis than the arteries in the same region.

Long-standing PV stenosis can lead to portal hypertension, splenomegaly, and gastrointestinal bleeding. In less serious cases of PV stenosis, the patients may not complain of any clinical symptoms, whereas in more severe cases lifethreatening symptoms such as upper gastrointestinal hemorrhaging might occur. Treatment is necessary in such cases.

Jejunal resection is a useful surgical approach for controlling hemorrhaging from jejunal varices. However, it carries a high risk of recurrent bleeding, and involves the cutting off of the collateral vessels. On the other hand, portosystemic shunting procedures can be used to decrease the blood flow through jejunal varices, but this results in a reduction in portal flow in the liver and is associated with encephalopathy [15] [16].

Surgical treatment for PV stenosis is technically difficult and often involves major blood loss. Since the study by Olcott et al. [17], there have been several reports about the insertion of metallic stents after PV angioplasty to relieve portal hypertension [18] [19]. The indications for this procedure have not yet been clarified; however, interventional radiology including this method should be considered for patients who develop symptomatic portal hypertension.

\section{Conclusion}

In the present small series, a correlation was detected between the degree of PV stenosis and the occurrence of postoperative complications after pancreatobiliary surgery. Clinicians should keep in mind that the PV can narrow in cases involving grade B or C PF or intra-abdominal infections. After pancreatobiliary surgery, careful postoperative surveillance including periodic CT examinations is recommended.

\section{Consent}

Written informed consent was obtained from the patient for publication of the report any accompanying images.

\section{Conflict of Interest}

All authors have no conflict of interest. 


\section{References}

[1] Nakao, A., Kanzaki, A., Fujii, T., Kodera, Y., Yamada, S., Sugimoto, H., Nomoto, S., Nakamura, S., Morita, S. and Takeda, S. (2012) Correlation between Radiographic Classification and Pathological Grade of Portal Vein Wall Invasion in Pancreatic Head Cancer. Annals of Surgery, 255, 103-108. https://doi.org/10.1097/SLA.0b013e318237872e

[2] Hoffer, E.K., Krohmer, S., Gemery, J., Zaki, B. and Pipas, J.M. (2009) Endovascular Recanalization of Symptomatic Portomesenteric Venous Obstruction after Pancreaticoduodenectomy and Radiation. Journal of Vascular and Interventional Radiolo$g y, 20,1633-1637$.

[3] Tsuruga, Y., Kamachi, H., Wakayama, K., Kakisaka, T., Yokoo, H., Kamiyama, T. and Taketomi, A. (2013) Portal Vein Stenosis after Pancreatectomy Following Neoadjuvant Chemoradiation Therapy for Pancreatic Cancer. World Journal of Gastroenterology, 28, 2569-2573. https://doi.org/10.3748/wjg.v19.i16.2569

[4] Settmacher, U., Nussler, N.C., Glanemann, M., Haase, R., Heise, M., Bechstein, W.O. and Neuhaus, P. (2000) Venous Complications after Orthotopic Liver Transplantation. Clinical Transplantation, 14, 235-241. https://doi.org/10.1034/j.1399-0012.2000.140309.x

[5] Kim, P.T., Wei, A.C., Atenafu, E.G., Cavallucci, D., Cleary, S.P., Moulton, C.A., Greig, P.D., Gallinger, S., Serra, S. and McGilvray, I.D. (2013) Planned versus Unplanned Portal Vein Resections during Pancreaticoduodenectomy for Adenocarcinoma. British Journal of Surgery, 100, 1349-1356. https://doi.org/10.1002/bjs.9222

[6] Yamashita, Y., Ryo, H. and Takasaki, K. (2004) Clinical Study of Transient Portal Vein Stenosis Induced after Pancreatic Head Resection. Surgery Today, 34, 925-931. https://doi.org/10.1007/s00595-004-2848-8

[7] Wei, B.J., Zhai, R.Y., Wang, J.F., Dai, D.K. and Yu, P. (2009) Percutaneous Portal Venoplasty and Stenting for Anastomotic Stenosis after Liver Transplantation. World Journal of Gastroenterology, 15, 1880-1885.

https://doi.org/10.3748/wjg.15.1880

[8] Kim, B.S., Kim, T.K., Jung, D.J., Kim, J.H., Bae, I.Y., Sung, K.B., Kim, P.N., Ha, H.K., Lee, S.G. and Lee, M.G. (2003) Vascular Complications after Living Related Liver Transplantation: Evaluation with Gadolinium-Enhanced Three-Dimensional MR Angiography. American Journal of Roentgenology, 181, 467-474. https://doi.org/10.2214/ajr.181.2.1810467

[9] Bassi, C., Dervenis, C., Butturini, G., Fingerhut, A., Yeo, C., Izbicki, J., Neoptolemos, J., Sarr, M., Traverso, W. and Buchler, M. (2005) International Study Group on Pancreatic Fistula Definition: Postoperative Pancreatic Fistula: An International Study Group (ISGPF) Definition. Surgery, 138, 8-13.

[10] Dindo, D., Demartines, N. and Clavien, P.A. (2004) Classification of Surgical Complications: A New Proposal with Evaluation in a Cohort of 6336 Patients and Results of a Survey. Annals of Surgery, 240, 205-213.

https://doi.org/10.1097/01.sla.0000133083.54934.ae

[11] Lee, J.H., Hwang, D.W., Lee, S.Y., Hwang, J.W., Song, D.K., Gwon, D.I., Shin, J.H., Ko, G.Y., Park, K.M. and Lee, Y.J. (2012) Clinical Features and Management of Pseudoaneurysmal Bleeding after Pancreatoduodenectomy. The American Surgeon, 78, 309-317.

[12] Kawai, M., Kondo, S., Yamaue, H., Wada, K., Sano, K., Motoi, F., Unno, M., Satoi, S., Kwon, A.H., Hatori, T., Yamamoto, M., Matsumoto, J., Murakami, Y., Doi, R., Ito, M., Miyakawa, S., Shinchi, H., Natsugoe, S., Nakagawara, H., Ohta, T. and Ta- 
kada, T. (2011) Predictive Risk Factor for Clinically Relevant Pancreatic Fistula Analyzed in 1,239 Patients with Pancreaticoduodenectomy: Multicenter Data Collection as a Project Study of Pancreatic Surgery by the Japanese Society of Hepato-Biliary-Pancreatic Surgery. Journal of Hepato-Biliary-Pancreatic Sciences, 18, 601-608. https://doi.org/10.1007/s00534-011-0373-x

[13] Kaneko, T., Nakao, A., Inoue, S., Harada, A., Nonami, T., Itoh, S., Endo, T. and Takagi, H. (1995) Intraportal Endovascular Ultrasonography in the Diagnosis of Portal Vein Invasion by Pancreatobiliary Carcinoma. Annals of Surgery, 222, 711-718. https://doi.org/10.1097/00000658-199512000-00004

[14] Bessa, X., Callaghan, E., Balleste, B., Nieto, M., Seoane, A., Panades, A., Vazquez, D.J., Andreu, M. and Bory, F. (2006) Applicability of the Rockall Score in Patients Undergoing Endoscopic Therapy for Upper Gastrointestinal Bleeding. Digestive and Liver Disease, 38, 12-17.

[15] Cohen, J., Edelman, R.R. and Chopra, S. (1992) Portal Vein Thrombosis: A Review. American Journal of Medicine, 92, 173-182.

[16] Senyuz, O.F., Yesildag, E., Emir, H., Tekant, G., Yeker, Y. and Bozkurt, P. (2001) Sugiura Procedure in Portal Hypertensive Children. Journal of Hepato-BiliaryPancreatic Surgery, 8, 245-249. https://doi.org/10.1007/s005340170024

[17] Olcott, E.W., Ring, E.J., Roberts, J.P., Ascher, N.L., Lake, J.R. and Gordon, R.L. (1990) Percutaneous Transhepatic Portal Vein Angioplasty and Stent Placement after Liver Transplantation: Early Experience. Journal of Vascular and Interventional Radiology, 1, 17-22.

[18] Hiraoka, K., Kondo, S., Ambo, Y., Hirano, S., Omi, M., Okushiba, S. and Katoh, H. (2001) Portal Venous Dilatation and Stenting of Bleeding Jejunal Varices: Report of Two Cases. Surgery Today, 31, 1008-1011. https://doi.org/10.1007/s005950170013

[19] Ota, S., Suzuki, S., Mitsuoka, H., Unno, N., Inagawa, S., Takehara, Y., Sakaguchi, T., Konno, H. and Nakamura, S. (2005) Effect of a Portal Venous Stent for Gastrointestinal Hemorrhage from Jejunal Varices Caused by Portal Hypertension after Pancreaticoduodenectomy. Journal of Hepato-Biliary-Pancreatic Surgery, 12, 88-92. https://doi.org/10.1007/s00534-004-0941-4

Scientific Research Publishing

\section{Submit or recommend next manuscript to SCIRP and we will provide best service for you:}

Accepting pre-submission inquiries through Email, Facebook, LinkedIn, Twitter, etc. A wide selection of journals (inclusive of 9 subjects, more than 200 journals)

Providing 24-hour high-quality service

User-friendly online submission system

Fair and swift peer-review system

Efficient typesetting and proofreading procedure

Display of the result of downloads and visits, as well as the number of cited articles

Maximum dissemination of your research work

Submit your manuscript at: http://papersubmission.scirp.org/

Or contact ss@scirp.org 